\title{
Shp2-Dependent ERK Signaling Is Essential for Induction of Bergmann Glia and Foliation of the Cerebellum
}

\author{
Kairong Li, ${ }^{1 \star}$ Alan W. Leung, ${ }^{1 \star}$ Qiuxia Guo, ${ }^{1}$ Wentian Yang, ${ }^{2}$ and James Y. H. Li ${ }^{1}$ \\ ${ }^{1}$ Department of Genetics and Developmental Biology, University of Connecticut Health Center, Farmington, Connecticut 06030-6403 and ${ }^{2}$ Department of \\ Orthopedics, Brown University, Providence, Rhode Island 0912
}

Folding of the cortex and the persistence of radial glia (RG)-like cells called Bergmann glia (BG) are hallmarks of the mammalian cerebellum. Similar to basal RG in the embryonic neocortex, BG maintain only basal processes and continuously express neural stem cell markers. Past studies had focused on the function of BG in granule cell migration and how granule cell progenitors (GCP) regulate cerebellar foliation. The molecular control of BG generation and its role in cerebellar foliation are less understood. Here, we have analyzed the function of the protein tyrosine phosphatase Shp2 in mice by deleting its gene Ptpn11 in the entire cerebellum or selectively in the GCP lineage. Deleting Ptpn11 in the entire cerebellum by En1-cre blocks transformation of RG into BG but preserves other major cerebellar cell types. In the absence of BG, inward invagination of GCP persists but is uncoupled from the folding of the Purkinje cell layer and the basement membrane, leading to disorganized lamination and an absence of cerebellar folia. In contrast, removing Ptpn11 in the GCP lineage by Atoh1-cre has no effect on cerebellar development, indicating that Shp2 is not cell autonomously required in GCP. Furthermore, we demonstrate that Ptpn11 interacts with Fgf8 and is essential for ERK activation in RG and nascent BG. Finally, expressing constitutively active MEK1 rescues BG formation and cerebellar foliation in Shp2-deficient cerebella. Our results demonstrate an essential role of Shp2 in BG specification via fibroblast growth factor/extracellular signal-regulated protein kinase signaling, and reveal a crucial function of BG in organizing cerebellar foliation.

Key words: Bergmann glia; cerebellum; extracellular signal-regulated kinases; mouse; radial glia; stem cell

\section{Introduction}

The adult cerebellar cortex is a trilaminar structure comprised of a monolayer of Purkinje cells (PCL) containing the somata of Purkinje neurons and Bergmann glia (BG) sandwiched between an internal granule cell layer and an outer molecular layer containing interneurons, granule cell axons, Purkinje dendrites, and BG radial fibers (Hatten, 1999; Wang and Zoghbi, 2001). Except for granule cells, which arise from the rhombic lip, the major cerebellar cell types including BG are generated from radial glia (RG) within the ventricular zone (VZ). During the RG-to-BG

Received Aug. 9, 2013; revised Nov. 24, 2013; accepted Nov. 30, 2013.

Author contributions: J.Y.H.L. designed research; K.L., A.W.L., Q.G., and J.Y.H.L. performed research; W.Y. contributed unpublished reagents/analytic tools; K.L., A.W.L., Q.G., and J.Y.H.L. analyzed data; K.L., A.W.L., and J.Y.H.L. wrote the paper.

This work was supported by grants from the National Institutes of Health (R01MH094914) and the Connecticut State Stem Cell Program (10SCB30-UCHC) to J.Y.H.L. We thank Drs. Fen Wang Lin Gan and Ryoichiro Kageyama for providing the Fgfr 1/2/3-CKO cerebellar samples, Atoh $7^{\text {cre }}$ knock-in mouse line, and anti-Hes1 antiserum, respectively. The monoclonal anti-NF165kDa antibody (2H3) and Pax6 were obtained through the Developmental Studies Hybridoma Bank under the auspices of the National Institute of Child Health and Human Development and maintained by The University of lowa (lowa City, IA).

${ }^{*}$ K.L. and A.W.L. contributed equally to this work.

The authors declare no competing financial interests.

Correspondence should be addressed to James Y.H. Li, Department of Genetics and Developmental Biology, University of Connecticut Health Center, 400 Farmington Avenue, Farmington, СT 06030-6403. E-mail: jali@uchc.edu.

A.W. Leung's present address: Department of Molecular Cellular and Developmental Biology, Yale University, 266 Whitney Avenue, New Haven, CT 06511.

DOI:10.1523/JNEUROSCI.3476-13.2014

Copyright $\odot 2014$ the authors $\quad 0270-6474 / 14 / 340922-10 \$ 15.00 / 0$ transformation, which occurs between mouse embryonic day 14.5 and 18.5 (E14.5 and 18.5), BG maintain the RG basal processes and relocate their soma from the VZ to the future PCL (Yuasa, 1996). After birth, the BG radial fibers facilitate inward migration of differentiating granule cell progenitors (GCP) from the external granular layer (EGL) to form the internal granule layer (Yamada and Watanabe, 2002; Xu et al., 2013). In the adult cerebellum, BG maintain structural integrity and synaptic connections (Iino et al., 2001; Yamada and Watanabe, 2002), and have been proposed to act as stem cells (Sottile et al., 2006; Alcock et al., 2007; Alcock and Sottile, 2009; Koirala and Corfas, 2010). The molecular cues driving RG-to-BG transformation remain elusive.

In amniotes, precisely timed and regionally defined folding of the cerebellar cortex results in an elaborate set of folia. GCP accumulation and invagination at the prospective fissures between the folia is believed to be the driving force behind the formation of the anchoring centers (Sudarov and Joyner, 2007). Concurrent with the development of the anchoring center, extensive rearrangements of BG fibers and cell bodies were also observed at the base of the prospective fissures ( $\mathrm{Su}$ darov and Joyner, 2007). Identifying a mutation that specifically ablates BG would determine BG functions in the initiation of the cerebellar foliation.

The protein tyrosine phosphatase Shp2 (encoded by Ptph11) modulates diverse signaling pathways (Feng, 2007; Yang et al., 2013). Shp2 dysregulation contributes to developmental syn- 

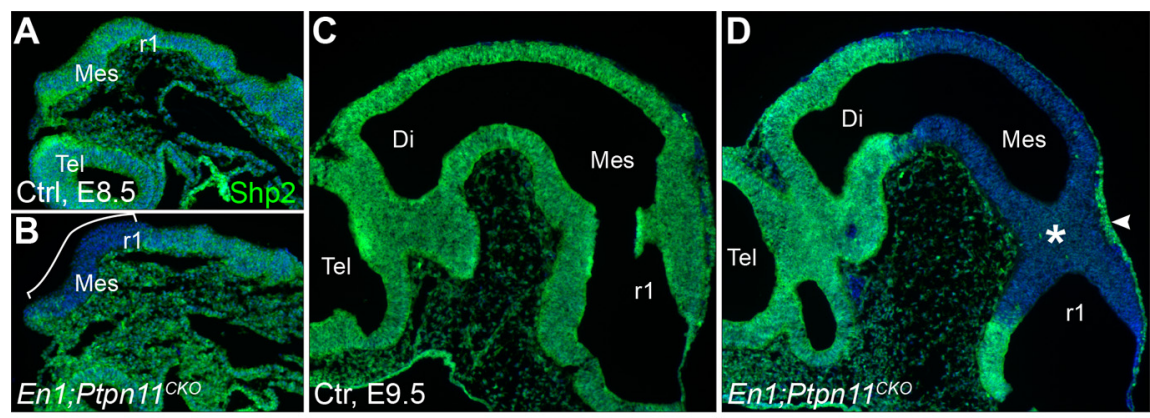

\section{Materials and Methods}

Generation and maintenance of mouse lines. All animal procedures described herein were approved by the Animal Care Committee at the University of Connecticut Health Center. Generation and PCR genotyping of $E n 1^{c r e /+}$ and the conditional floxed $(f l)$ mutant allele Ptpn $11^{+/ f l}$ mice were described previously (Kimmel et al., 2000; Yang et al., 2006). R26 ${ }^{M E K 1 D D}$ (C57BL/6-

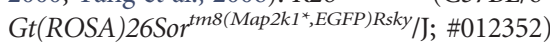
mouse line was obtained from The Jackson Laboratory and the primer sequences for PCR

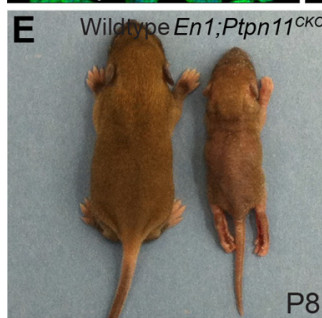

H

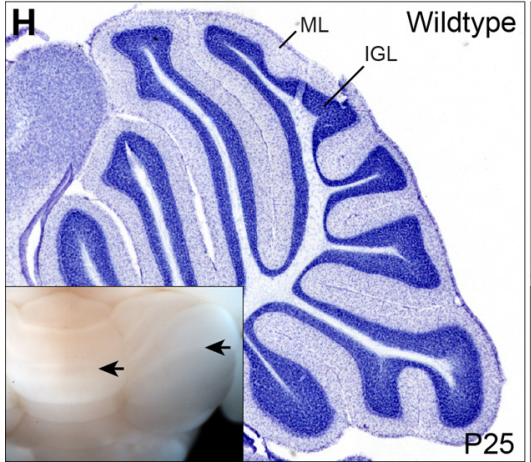

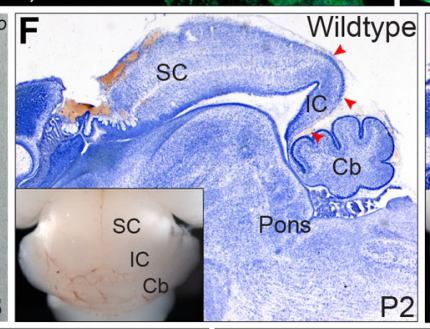

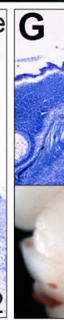

En1;Ptpn11cisc
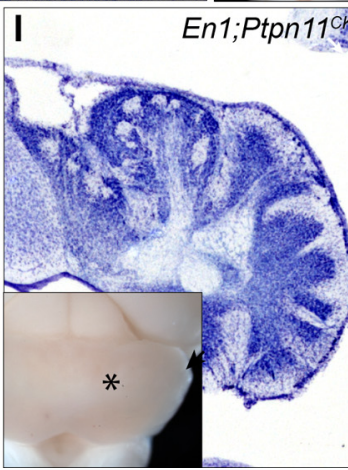

Figure 1. Specific deletion of Shp2 in midbrain and cerebellar progenitors results in a truncated midbrain and disorganized cerebellar cortex. $\boldsymbol{A}-\boldsymbol{D}$, IF for Shp2 on sagittal sections of E8.5 $(\boldsymbol{A}, \boldsymbol{B})$ and E9.5 $(\boldsymbol{C}, \boldsymbol{D})$ embryos. The bracket and asterisk indicate the loss of Shp2; the arrowhead denotes the presence of Shp2 in the meninges where $E n 1^{C r e}$ is not expressed. $\boldsymbol{E}$, Dorsal view of wild-typeand $E n 1 ; P \operatorname{tpn} 11^{\mathrm{CKO}}$ mice at P8. F-I, Niss staining of sagittal sections of the cerebellum (Cb). Insets show the whole-mount brains; the asterisk indicates the lack of cerebellar fissures (arrow). Arrowheads in $\boldsymbol{F}$ indicate the inferior colliculus (IC) that is missing in the mutants. $\boldsymbol{J}, \boldsymbol{K}, \mathrm{IF}$ for Calbindin (Calb) on wild-type $(\boldsymbol{J})$ and En1;Ptpn $11^{C K O}(\boldsymbol{K})$ cerebellum atP25. Note the abnormal arrangement of Purkinje neurons (arrows), the molecular layer (ML; containing the dendrites of Purkinje cells in green), and the internal granule layer (IGL; densely packed nuclei in blue) in the mutant cerebellum. Di, diencephalon; Mes, mesencephalon; r1, rhombomere 1;SC, superior colliculus; Tel, telencephalon. Scale bar, $A, B, 180 \mu \mathrm{m}$; $\boldsymbol{C}, \boldsymbol{D}, 430 \mu \mathrm{m} ; \boldsymbol{F}, \mathbf{G}, 720 \mu \mathrm{m} ; \boldsymbol{H}, \boldsymbol{I}, 625 \mu \mathrm{m} ; \boldsymbol{J}, \boldsymbol{K}, 50 \mu \mathrm{m}$.

dromes and cancers (Tartaglia et al., 2001; Chan and Feng, 2007; Mohi and Neel, 2007). In the mouse neocortex, Ptpn11 deletion altered extracellular signal-regulated protein kinase (ERK) and Stat 3 signaling leading to imbalanced genesis of neurons and glia (Gauthier et al., 2007; Ke et al., 2007). Furthermore, Nestin-cremediated deletion of Ptpn11 reduces the extent of foliation and led to disorganized lamination in the mouse cerebellum, as well as defective BG fiber organization (Hagihara et al., 2009). Based on in vitro data, the cerebellar phenotype was attributed to a cell-autonomous requirement of Shp2 for GCP migration via Cxcl12/Cxcr4 signaling (Hagihara et al., 2009). However, it remains to be determined whether Shp2 indirectly regulates GCP migration through controlling BG development.

To investigate the molecular mechanism underlying BG generation and to examine the intrinsic role of Shp2 in the GCP lineage, we have used tissue-specific knock-outs to define the primary cellular target and the signaling pathway regulated by Shp2 in the developing cerebellum. We have shown that Shp2 is not cell autonomously required in the GCP lineage. Our study has uncovered a crucial role of the fibroblast growth factor (FGF)/Shp2/ERK pathway in BG generation, and a previously unrecognized function of $\mathrm{BG}$ in cerebellar foliation.
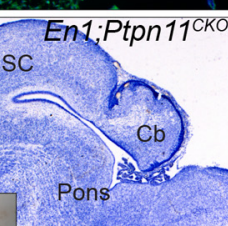

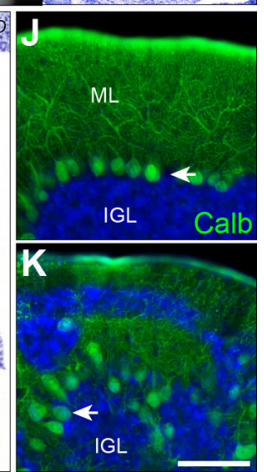

genotyping are provided in http://www.jax. org. The $R 26^{M E K 1 D D}$ is a conditional gain-offunction allele containing a Neo-STOP cassette upstream of a $M E K 1^{D D} \mathrm{cDNA}$ in the Rosa26 locus so that cre-mediated recombination leads to expression of $M E K 1^{D D}$ (Srinivasan et al., 2009). Atoh $1^{\text {cre/+ }}$ mice were kindly provided by Dr. Lin Gan (University of Rochester, New York). The Atoh $1^{\text {cre }}$ is a knock-in allele, in which the entire Atoh 1 coding sequence was replaced with the cre coding sequence (Yang et al., 2010). All mouse strains were maintained on a CD1 genetic background and mice of either sex were analyzed (Charles River Laboratories). Noon of the day when a vaginal plug was detected was designated as E0.5 in staging of embryos. $P \operatorname{tpn} 11^{f l / f l}$ and $E n 1^{c r e /+} ; P t p n 11^{f l /+}$ mice were viable, fertile, and did not display any detectable embryonic and postnatal phenotypes, and were thus treated as wild-type controls in this study.

Western blot. The posterior mesencephalon and cerebellar anlagen of E13.5 wild-type and $E n 1^{c r e /+} ; P t p n 11^{f l f l}$ mutants were obtained by microdissection. Liquid nitrogen-frozen tissues were lysed in radioimmunoprecipitation assay buffer (Pierce). Proteins $(20 \mu \mathrm{g})$ were separated on $10 \%$ reducing gels, transferred onto nitrocellulose membranes, and detected using DyLight 680/800 Western blotting kits (Thermo Scientific) by antibodies (Cell Signaling Technology) against AKT, pAKT(S473), STAT3, pSTAT3(Y705), ERK, pERK1/2 (T202/Y204), and $\beta$-actin. Protein inputs were normalized using $\beta$-actin. The amount of unphosphorylated and phosphorylated forms of AKT, STAT3, and ERK were quantified using ImageJ.

Histological analyses. Embryonic brains were dissected and fixed in $4 \%$ paraformaldehyde (PFA) in PBS at $4^{\circ} \mathrm{C}$ overnight. Postnatal mice were perfused with $4 \%$ PFA before dissection and processed as above. All brains were cryoprotected with a sucrose gradient followed by embedding in Optical Cutting Temperature Compound (Sakura Finetek). Serial sections of $16 \mu \mathrm{m}$ (embryonic stages) or $50 \mu \mathrm{m}$ (postnatal stages) thickness were prepared using a cryostat (CM3050 S; Leica). Detailed immunohistological and in situ hybridization protocols are described on the Li lab website (http://lilab.uchc.edu/protocols/index.html). The following antibodies were used: rabbit anti-laminin (1:1000; Sigma), rabbit anti-caspase 3 (1:500; Cell Signaling Technology), rabbit anti-Sox2 (1: 200; Invitrogen), rabbit anti-BLBP (1:1000; Millipore), rabbit anti-Sox9 (1:1000; Millipore), guinea pig anti-BLBP (1:500; Frontier Institute), mouse anti-Nestin (1:500; Developmental Studies Hybridoma Bank; DSHB), anti-mouse Pax6 (1:100; DSHB), mouse anti-RC2 (1:100; DSHB), mouse anti-Tag1 (1:100; DSHB), mouse anti-TuJ1 (1:2000; Covance), rabbit anti-Pax2 (1:200, Zymed), rabbit anti-calbindin (1:3000; Swant), rat anti-Ki67 (1:100; Dako Cytomation), and rabbit anti-GFAP (1:1000; Dako Cytomation). Alexa Fluor secondary antibodies (Invitro- 
gen) were used. Tyramide Signal Amplification system (PerkinElmer) was used for rabbit antipERK (1:1000; Cell Signaling Technology) and rabbit anti-Ptpn11 (1:2000; Promega) antibodies. Nuclei were counterstained with Hoechst 33342 (Invitrogen). Slides were mounted with Fluoromount-G (SouthernBiotech). Images were taken using a Zeiss Imager M1 or a LSM510 confocal microscope.

\section{Results}

Shp2 is essential for the expansion and foliation of the cerebellar cortex

$E n 1^{\text {cre }}$ mice express cre DNA recombinase in the neural plate area that forms the future midbrain and cerebellum as early as E8.0 (Li et al., 2002). To remove Ptpn11 from midbrain and cerebellum progenitors, we crossed En $1^{\text {cre }}$ mice with mice carrying a floxed Ptpn11 $\left(P t p n 11^{f l}\right)$ allele to generate the $E n 1^{\text {cre/+}} ; P t p n 11^{f l f l}$ (designated as En 1;Ptpn $11^{C K O}$ ) mice. Immunostaining showed that the Shp 2 protein was ubiquitously present in wild-type embryos (Fig. 1A,C), and specifically deleted in the neural plate region that corresponds to the prospective midbrain and cerebellum in En1;Ptpn 11 ${ }^{\text {CKO }}$ embryos as early as E8.5 (Fig. $1 B, D$ ). En1;Ptpn $11^{\text {CKO }}$ mice were smaller in size and displayed ataxic behaviors (Fig. 1E; data not shown). At birth, En1;Ptpn11 $1^{C K O}$ mice had a truncated midbrain and a slightly smaller cerebellum (Fig. $1 G$ ). In contrast to the control, the En 1;Ptpn11 ${ }^{\text {CKO }}$ cerebellum at postnatal day 25 (P25) was stunted and displayed a remarkably smooth surface without visible folia (Fig. $1 H$, I, insets). Histological analyses revealed disorganized layering of Purkinje and granule cells in the mutant cerebellum (Fig. $1 H-K$ ).

The stereotypical folia of the mouse cerebellum are established from E18.5 to P25 (Sudarov and Joyner, 2007). During the anchoring center formation, the EGL folds inward together with the overlaying pial basement membrane and the underlying PCL, as revealed by immunofluorescence (IF) for Pax6, laminin, Calbindin D-28K (Calb), and BLBP, which specifically demarcate the granule cells, basement membrane, Purkinje cells, and BG, respectively (Fig. $2 A, C-D^{\prime \prime}$ ). All fissures were outlined by the basement membrane with anchoring $\mathrm{BLBP}^{+}$BG fibers, which formed a well organized parallel scaffold in the molecular layer (Fig. $2 C, D, I)$. In the vermis region of the En1;Ptpn $11^{C K O}$ cerebellum, the inward GCP accumulation persisted (Fig. $2 \mathrm{~B}, \mathrm{E}-\mathrm{H}$ ). However, the invaginated EGL abnormally penetrated through the PCL without an accompanied folding of the PCL (Fig. 2B). In En1;Ptpn $11^{C K O}$ mice at P2, although the pial basement membrane was present on the cerebellar surface, it was spotted or absent within the invaginated EGL (Fig. $2 E-H^{\prime}$ ). Notably, few $\mathrm{BLBP}^{+}$cell bodies and fibers were detected in the En1;Ptpn $11^{\text {CKO }}$ cerebellum, but they were normally present in the pons and other brain structures (Fig. 2E), suggesting a lack of BG in the mutants (see below). Therefore, Ptpn11 deletion disrupts cerebellar fissure formation by uncoupling the folding of EGL from that of the PCL and the pial basement membrane.

\section{Shp2 is dispensable in the rhombic lip and the external granule layer}

The proper formation and development of the EGL are important for the cerebellar foliation process (Corrales et al., 2004; Sudarov and Joyner, 2007). We therefore examined granule cell development in En1;Ptpn $11^{\text {CKO }}$ using lineage-specific and differentiation markers for GCP. Analyses of Atoh 1 and Pax6, by in situ hybridization (ISH) and IF, respectively, showed that the EGL was formed on the surface of the cerebellum of wild-type and En1;Ptpn 11 ${ }^{\text {CKO }}$ embryos at E14.5 (Fig. 3A,B). Compared with that of the littermate control, the EGL appeared thicker in En1; Ptpn $11^{C K O}$ cerebella between E16.5 and P2, and became thinner after P6 (Fig. $3 A, B$, insets; $C, D$ ). The thinner EGL is probably not caused by abnormal cell death as IF for activated caspase 3 (Casp3) has revealed similar numbers of apoptotic cells between the control and mutant cerebella at both P6 and P8 (data not shown). To examine the proliferation and differentiation of GCP in the En1;Ptpn11 ${ }^{\text {CKO }}$ cerebellum, we performed IF for Ki67, Tag1, and Tuj1 triple labeling. In neonatal mice, Ki67 is expressed in proliferating GCP in the outer EGL, Tag1 in differentiating granule cells emerging in the premigratory zone in the inner EGL, and TuJ1 in postmitotic granule neurons (Fig. $3 E, G$ ). In the EGL of the En1;Ptpn11 ${ }^{C K O}$ cerebellum, the $\mathrm{Ki}^{+} 7^{+}$proliferative layer appeared thinner compared with that in the control and Tag $1^{+}$ cells were abnormally present in the outer EGL intermixing with $\mathrm{Ki} 67^{+}$cells; these phenotypes became more pronounced at P15 (Fig. $3 F, H$ ). The accumulation of Tag $1^{+}$cells within the outer 


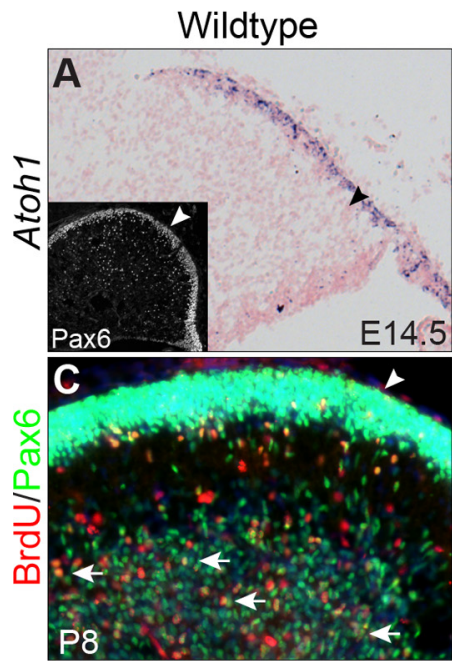

Wildtype

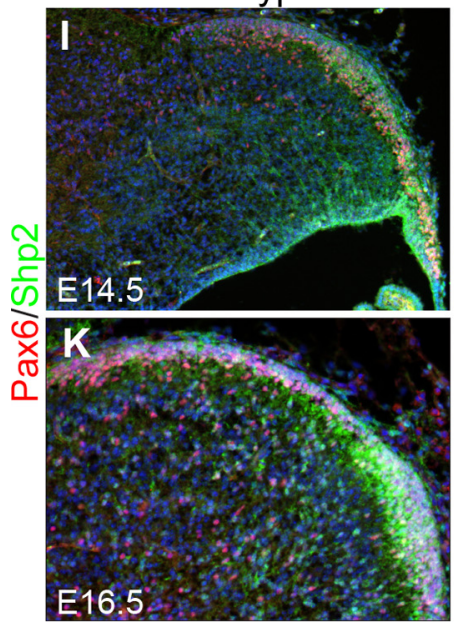

En1;Ptpn $11^{\text {CKO }}$

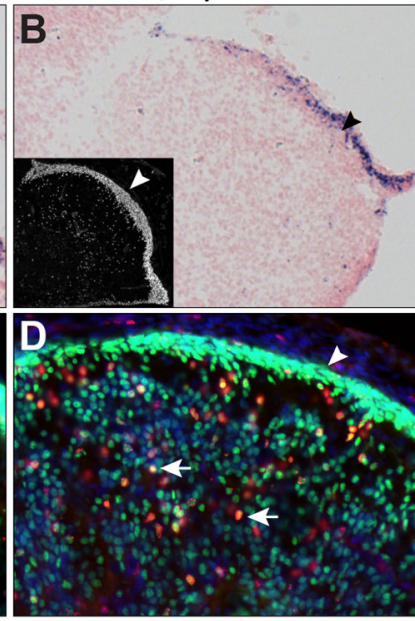

Atoh1;Ptpn11 CKO

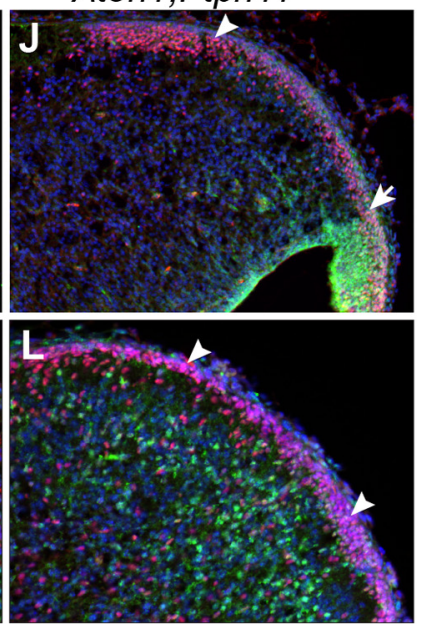

Wildtype

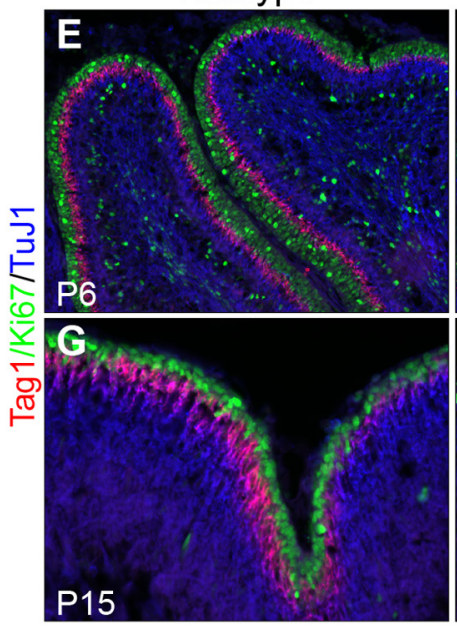

Wildtype
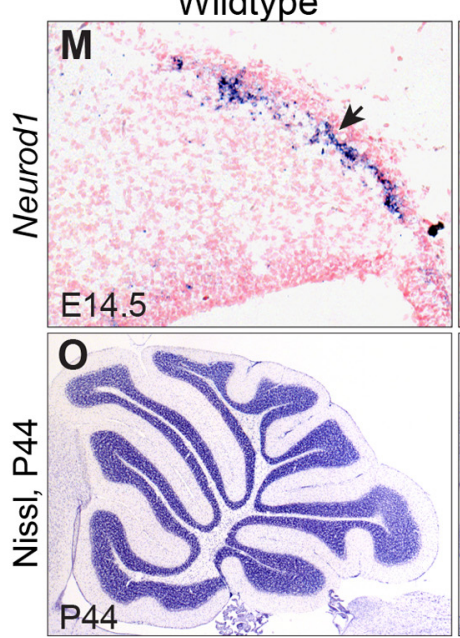

En1;Ptpn11 CKO

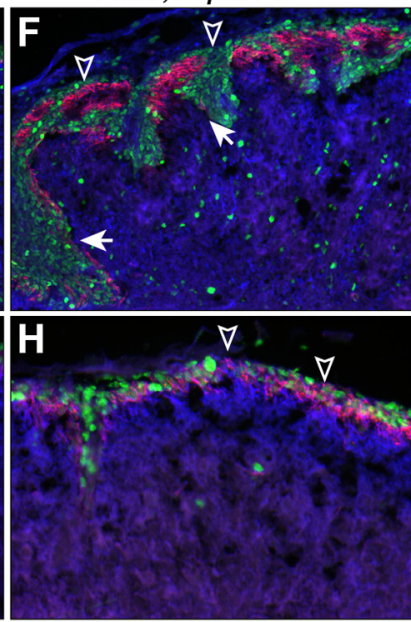

Atoh1;Ptpn11 cko
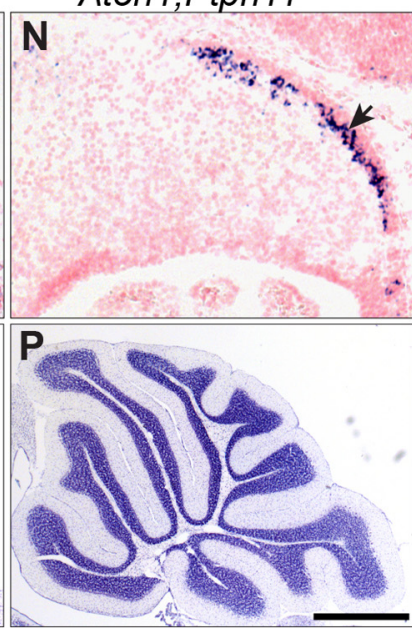

Figure 3. Ptpn11 is not intrinsically required in granule cell development. $\boldsymbol{A}, \boldsymbol{B}, \mathrm{ISH}$ for Atoh1 on sections of wild-type $(\boldsymbol{A})$ and En 1; Ptpn $11^{\text {CKO }}$ (B) E14.5 cerebella. Insets show IF for Pax6 on E16.5 cerebellar sections. Arrowheads highlight the Atoh $1^{+}$and Pax6 ${ }^{+}$EGL. C $-\boldsymbol{H}$, IF analyses on sagittal sections of the cerebellum. Note that the EGL (arrowheads) of the En $1 ;$; Ptpn $11^{\text {CKO }}$ cerebellum is thickened at E16.5 (inset in $\boldsymbol{B}$ ) and becomes thinner at P8. Arrows show BrdU ${ }^{+} / \mathrm{Pax} 6^{+}$double-positive granule neurons; empty arrowheads denote the ectopic Tag $1^{+}$cells in the Ki67 ${ }^{+}$layer, which also appears thinner than that in the control, in the outer EGL. Arrows in $\boldsymbol{F}$ indicate the reduction or lack of Tag1 expression associated with the invaginated EGL. I- $L$, IF for Pax6 and Shp2 in wild-type and Atoh1; Ptpn 11 ${ }^{\mathrm{CKO}}$ cerebella at E14.5 and E16.5 as indicated. The arrow highlights the residual Shp2 in GCP near the rhombic lip; arrowheads show the absence of the protein specifically in the EGL farther away from the rhombic lip at E14.5 or throughout the EGL at E16.5. $\mathbf{M}, \mathbf{N}$, ISH for Neurod1 to show normal formation of the EGL (arrow) on E14.5 cerebellar sections. $\mathbf{O}, \boldsymbol{P}$, Nissl analyses of P44 cerebellar sections. Scale bar, $\boldsymbol{A}, \boldsymbol{B}, 190 \mu \mathrm{m} ; \boldsymbol{C}, \boldsymbol{D}, 139 \mu \mathrm{m} ; \boldsymbol{E}, \boldsymbol{F}, 100 \mu \mathrm{m} ; \boldsymbol{G}, \boldsymbol{H}, 322 \mu \mathrm{m} ; \boldsymbol{I}, \boldsymbol{J}, 154 \mu \mathrm{m} ; \boldsymbol{K}, \boldsymbol{L}, 105 \mu \mathrm{m} ; \boldsymbol{M}, \boldsymbol{N}, 650 \mu \mathrm{m} ; \mathbf{O}, \boldsymbol{P}, 500 \mu \mathrm{m}$.

EGL suggests that there might be premature differentiation of GCP in the En1;Ptpn11 ${ }^{\text {CKO }}$ cerebellum. To evaluate the inward migration of granule cells, we performed bromodeoxyuridine (BrdU) pulse chase experiments by injecting BrdU at P5 and performed double labeling of BrdU and Pax6 on P8 cerebellar sections. Pax6 is expressed strongly in the proliferating GCP and weakly in postmitotic granule neurons (Fig. $3 A$, inset; $C$ ). The GCP that underwent their last cell cycle at P5 and migrated internally were positive for both BrdU and Pax6, and were located mostly in the internal granule layer at P8 (Fig. 3C). Despite a reduction in numbers, granule neurons colabeling BrdU and Pax6 were detected in the cerebellar cortex away from the EGL in En1;Ptpn $11^{\text {CKO }}$ mice at P8 (Fig. 3D). Together, our data show that although the initial formation of the EGL is relatively intact before $\mathrm{P} 2$, the subsequent differentiation and migration of granule cells are disrupted in the En 1;Ptpn $11^{C K O}$ cerebellum. The decreased proliferation and enhanced differentiation of GCP in the EGL after P6 may account for the smaller size of En1;Ptpn11 ${ }^{\text {CKO }}$ cerebella.
To investigate the intrinsic requirement of Ptpn11 in GCP development, we crossed mice harboring the Ptpn $11^{f l}$ and $A t o h 1^{\text {cre }}$ alleles. The Atoh ${ }^{\text {cre }}$ allele contains a knock-in insertion of cre recombinase in the Atoh 1 locus such that recombination occurs within the rhombic lip and the EGL (Yang et al., 2010). To evaluate the deletion of Ptpn11 in the EGL, we examined Shp2 protein expression in the Atoh $1^{\text {crel+ }} ;$ Ptpn $11^{\text {fllfl }}$ (designated as Atoh1;Ptpn $11^{\text {CKO }}$ ) embryos. We found that Shp2 expression was mostly absent in the anterior part of the EGL, and residual Shp2 immunoreactivity was only detected in the progenitor pool of the rhombic lip in the Atoh $1^{\text {cre/+}}$; Ptpn $11^{f l f l}$ embryos at E14.5 (Fig. 3I,J). By E16.5, no Shp2 signals were detected in the EGL in the Atoh $1^{\text {cre/+ }} ;$ Ptpn $11^{\text {fl/fl }}$ embryos (Fig. 3I-L), demonstrating the specific deletion of Ptpn11 in the GCP lineage. Formation of EGL, as examined by Pax6 and Neurod1, was normal in Atoh1;Ptpn11 ${ }^{\text {CKO }}$ embryos (Fig. 3I-N). Furthermore, Nissl analysis showed that the formation of the cerebellar folia was indistinguishable between control and Atoh1; Ptpn $11^{\text {CKO }}$ mice at E18.5 and postnatal stages (Fig. 3O,P; data not shown). These data collectively demonstrate that Ptpn11 is dis- 

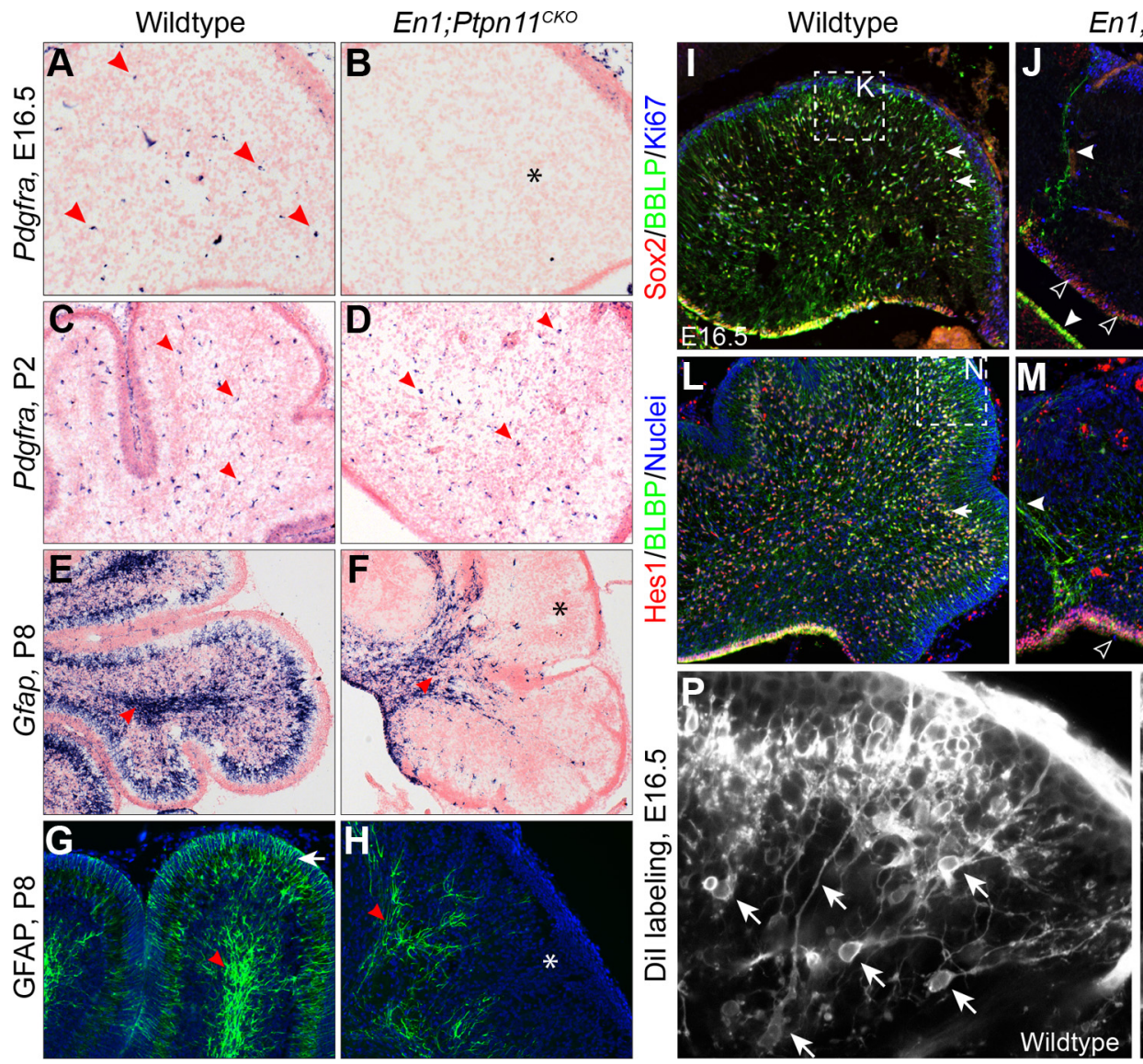

En1;Ptpn11 cko
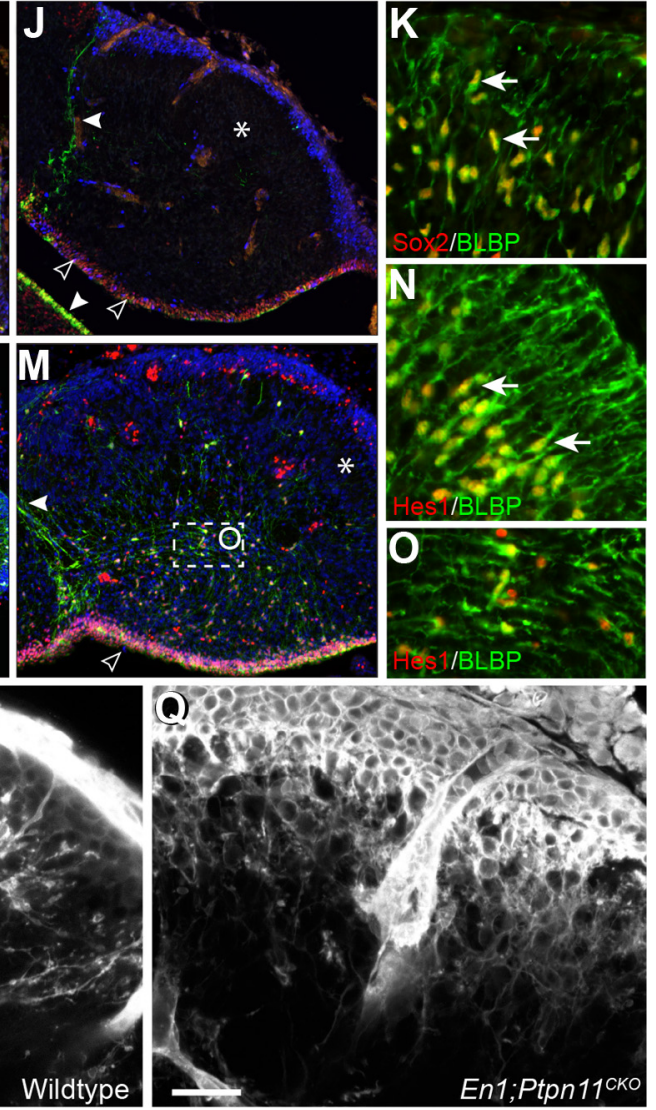

Figure 4. Ptpn11 deletion results in specific loss of BG. $\boldsymbol{A}-\boldsymbol{H}$, ISH for Pdgfra $(\boldsymbol{A}-\boldsymbol{D})$ and $G$ fap $(\boldsymbol{E}, \boldsymbol{F})$ and IF for GFAP $(\boldsymbol{G}, \boldsymbol{H})$ on sagittal sections of cerebella for the indicated genotypes and stages. Red arrowheads indicate Pdgfra ${ }^{+}$oligodendrocyte progenitors $(\boldsymbol{A}-\boldsymbol{D})$ or $G$ fap + astrocytes in the white matter $(\boldsymbol{E}, \boldsymbol{F})$; asterisks denote the lack of $P$ dgfra ${ }^{+}$cells in the E16.5 cerebellum $(\boldsymbol{B})$ or the lack of $\mathrm{Gfap}^{+}$cells in the cortical area of the P8 cerebellum $(\boldsymbol{F}, \boldsymbol{H})$ in En1;Ptpn11 ${ }^{C K O}$ mice. $\boldsymbol{I}-\mathbf{0}$, IF for the indicated markers on sagittal sections of E16.5 (I-K) and E18.5 ( $\left.\boldsymbol{L}-\mathbf{0}\right)$ cerebellum. Note that Sox2 ${ }^{+} / \mathrm{BLBP}^{+} / \mathrm{Ki} 7^{+}$and Hes1 ${ }^{+} / \mathrm{BLBP}^{+}$cells are mostly absent in the mantle area (asterisks), but persist in the VZ (empty arrowheads) of the En 1;Ptpn $11^{\mathrm{CKO}}$ cerebellum. Arrowheads denote BLBP fibers at the junction between the midbrain and cerebellum in $\boldsymbol{J}$ and $\boldsymbol{M}$, as well as BLBP expression in the VZ of the pons in $\boldsymbol{J}$. The boxed areas in $\boldsymbol{I}, \boldsymbol{L}$, and $\boldsymbol{M}$ are enlarged and shown in only green and red channels in $\boldsymbol{K}, \boldsymbol{N}$, and $\mathbf{O} . \boldsymbol{P}, \mathbf{Q}$, Cell labeling with Dil in wild-type $(\boldsymbol{P})$ and En1;Ptpn11 ${ }^{\mathrm{CKO}}$ cerebella $(\mathbf{Q})$ at E16.5. Note that putative BG (arrows) are seen in the wild-type but not in mutant cerebellum. Scale bar, $\boldsymbol{A}, \boldsymbol{B}, 120 \mu \mathrm{m} ; \boldsymbol{C}, \boldsymbol{D}, 190 \mu \mathrm{m} ; \boldsymbol{E}, \boldsymbol{F}, 300 \mu \mathrm{m} ; \boldsymbol{I}, \boldsymbol{J}, 130 \mu \mathrm{m} ; \boldsymbol{L}, \boldsymbol{M}, 200 \mu \mathrm{m}$.

pensable in GCP and suggest that the foliation defects found in En1;Ptpn $11^{\text {CKO }}$ cerebella were not caused by a cell-autonomous function of Ptpn11 in the GCP.

\section{Inactivation of Shp2 delays oligodendrocyte induction and abolishes BG formation}

The above findings suggest that Shp2 probably regulates cerebellar development through cells derived from the cerebellar VZ but not those from the rhombic lip. We therefore characterized cell types that are generated from the cerebellar VZ, including Purkinje neurons, interneurons, oligodendrocytes, and BG, in En1;Ptpn $11^{C K O}$ mutants. Examination of Purkinje cells and interneurons by IF for Calb and Pax2, respectively, showed that these neurons were readily detected in the En1;Ptpn $11^{C K O}$ cerebellum (Figs. $1 K, 2 B$ ). Oligodendrocyte progenitors, as revealed by ISH for Pdgfra, were missing in En1;Ptpn11 ${ }^{\text {CKO }}$ cerebella at E16.5 (Fig. $4 A, B$ ), but the density of $\mathrm{Pdgfra}^{+}$cells became comparable between wild-type and mutant cerebella at P2 (Fig. 4C,D), indicating that there was delayed induction of oligodendroglia. ISH for the astrocyte marker Gfap showed that astrocytes were present in the white matter of the mutant cerebellum; however, $\mathrm{Gfap}^{+}$cells were missing in the cerebellar cortex in the En1;Ptpn11 ${ }^{\text {CKO }}$ cerebellum (Fig. $4 E, F$ ). In agreement with the analysis of mRNA, immunostaining showed that $\mathrm{GFAP}^{+}$fibrous astrocytes were readily detected in the white matter of the control and mutant cerebella, but only the control cerebella had GFAP ${ }^{+}$BG and radial fibers in the molecular layer at P2 and P25 (Fig. 4G,H; data not shown).

To confirm a lack of BGs in the En1;Ptpn $11^{C K O}$ cerebellum, we performed additional markers analyses. BG were known to express neural progenitor markers in the postnatal cerebellum (Sottile et al., 2006; Alcock et al., 2007; Koirala and Corfas, 2010). Neural progenitor markers, Sox2, Sox9, and Hes1, and the proliferation marker Ki67 were expressed in the progenitors in the VZ, as well as in cells within the mantle zone of the cerebellum at E16.5 and E18.5 (Fig. 4I, K, $L, N$; data not shown). Importantly, the Sox ${ }^{+} /$ $\mathrm{Hes}^{+} / \mathrm{Ki} 7^{+}$cells in the subcortical area coexpressed BLBP and displayed unipolar processes extending to the pial surface, a hallmark of BG (Fig. $4 K, N$ ), demonstrating that BG already express neural progenitor markers in the embryonic cerebellum. In En1; Ptpn $11^{\text {CKO }}$ cerebella at E16.5, although Sox2 and Ki67 were normally expressed in the VZ, they were completely absent between the $\mathrm{VZ}$ and pial surface (Fig. $4 J$ ). Furthermore, BLBP expression was missing except for a few $\mathrm{BLBP}^{+}$fibers at the junction between the cerebellum and the midbrain, and the pons (Fig. 4J). Interestingly, in En1;Ptpn $11^{C K O}$ cerebella at E18.5, some Hes ${ }^{+}$/ $\mathrm{BLBP}^{+}$cells were delaminated from the VZ but their cellular processes were parallel to the $\mathrm{VZ}$, rather than extending to the pial surface (Fig. 4M,O). 


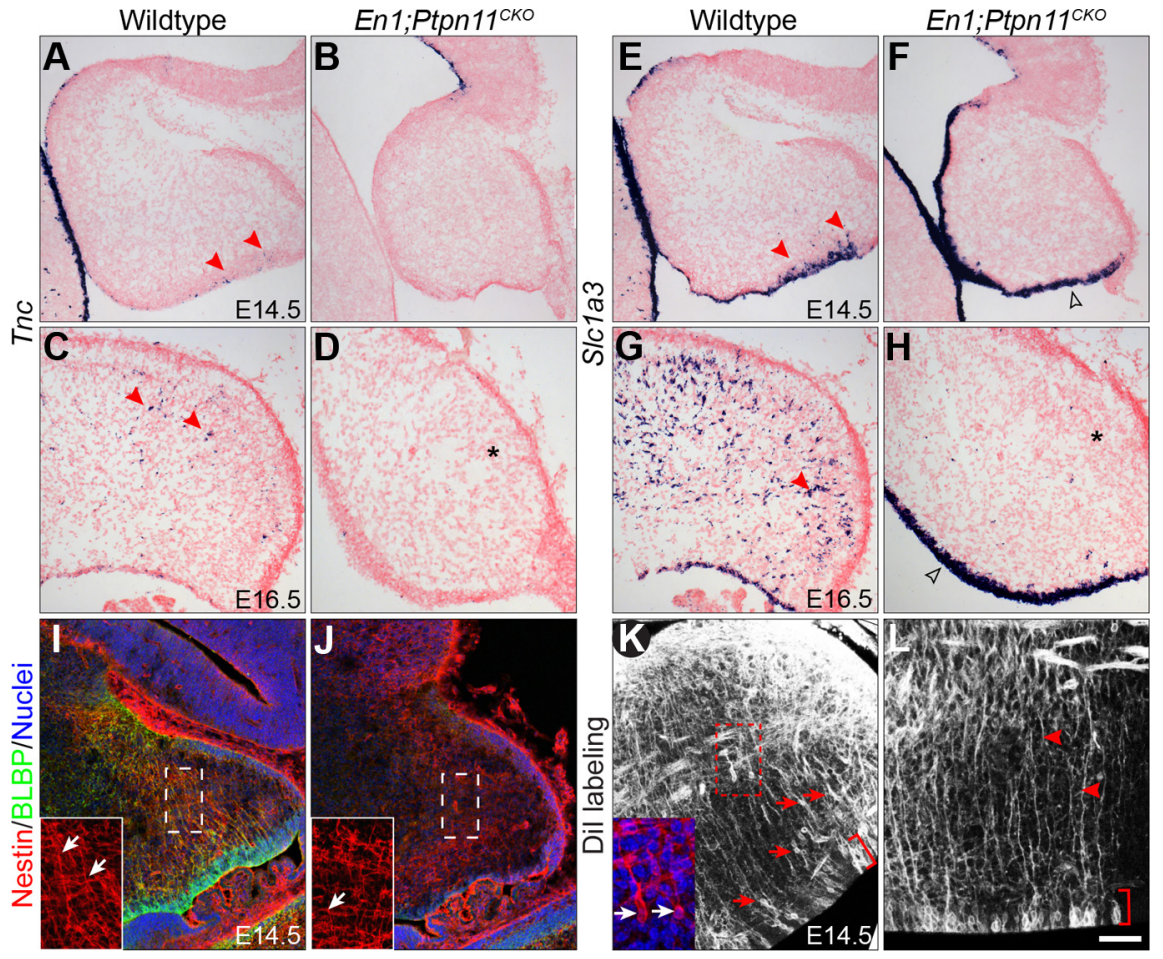

Figure 5. Deletion of Ptpn 11 blocks transformation of RG into BG. $\boldsymbol{A}-\boldsymbol{H}$, ISH for $\operatorname{TnC}(\boldsymbol{A}-\boldsymbol{D})$ and SIC 1 a $3(\boldsymbol{E}-\boldsymbol{H})$ on sagittal sections of the cerebellum for the indicated genotypes and stages. Arrowheads in $\boldsymbol{A}$ and $\boldsymbol{E}$ indicate nascent $B G$ that are delaminated from the VZ; empty arrowheads show enhanced SIc 193 expression in the VZ. Asterisks in $\boldsymbol{D}$ and $\boldsymbol{H}$ indicate the absence of putative BG marked by Inc or SIc1a3. I, J, IF for BLBP and Nestin on E14.5 sagittal cerebellar sections. Insets show only the Nestin staining enlarged from

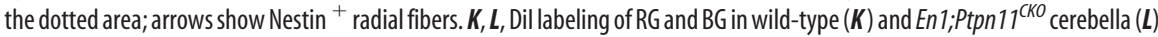
at E14.5. Brackets denote the VZ; arrows indicate the labeled BG that contain unipolar basal but no apical process. A dotted area in wild-type is enlarged and shown in the inset; arrowheads show the somata of BG in wild-type cerebella. Scale bar, $\boldsymbol{A}, \boldsymbol{B}, \boldsymbol{E}, \boldsymbol{F}, 70$ $\mu \mathrm{m} ; \boldsymbol{C}, \boldsymbol{D}, \mathbf{G}, \boldsymbol{H}, 95 \mu \mathrm{m} ; \boldsymbol{I}, \boldsymbol{J}, 20 \mu \mathrm{m} ; \boldsymbol{K}, \boldsymbol{L}, 50 \mu \mathrm{m}$.

To corroborate the marker analysis, we performed cell labeling by applying lipophilic dye DiI to the pial surface to label BG through their basal processes. In the wild-type cerebellum at E16.5, DiI labeled numerous presumptive BG, which resided in the subcortical region and displayed unipolar morphology with one or multiple long processes extending to the pial membrane (Fig. 4P). In contrast, the DiI labeling did not reveal any cells that resembled BG in the En1;Ptpn11 ${ }^{C K O}$ cerebellum at E16.5 $(n=3$; Fig. 4Q). Collectively, our data suggest that Ptpn11 deletion primarily affects $B G$ formation but preserves formation of the other major VZ-derived cell types.

\section{Inactivation of Shp2 blocks transformation of RG into BG}

We next sought to investigate if the lack of BG in the En1;Ptpn $11^{\text {CKO }}$ cerebellum might result from a failure of induction of BG. Tenasin C $(T n c)$ is considered one of the earliest markers for nascent BG (Yuasa, 1996). Tnc transcripts were first detected in the VZ near the posterior part of the cerebellum at E14.5, and later in the presumptive BG in the subcortical area at E16.5 (Fig. 5A,C). Tnc transcripts were completely missing in En1;Ptpn $11^{\text {CKO }}$ cerebella at E14.5 and E16.5 (Fig. 5B,D). Interestingly, ISH for Slcla3 (Glast), a marker for both RG and BG (Anthony et al., 2004), revealed that its expression was lost outside the VZ but enhanced in the VZ of En1;Ptpn11 ${ }^{\text {CKO }}$ cerebellum (Fig. 5E-H), suggesting that Ptpn11 deletion may have prevented RG from transforming into BG. Furthermore, we found that the immunoreactivity of BLBP and RC2, two known BG markers (Anthony et al., 2004), was absent in the En1;Ptpn11 ${ }^{\text {CKO }}$ cerebellum at E14.5 (Fig. 5J; data not shown). Interestingly, Nestin, which also marks the radial fibers of RG (Malatesta et al., 2003), was detected in both wild-type and En1;Ptpn11 ${ }^{C K O}$ cerebella at E14.5 (Fig. $5 I, J)$, indicating the presence of RG. To confirm that Ptpn11 deletion affects BG but not RG, we performed backfill labeling by applying DiI on the pial surface. In E14.5 wild-type cerebella, DiI labeled the basal processes as well as the somata within and away from the VZ, presumably RG and BG, respectively (Fig. $5 K$ ). In contrast, DiI labeling revealed abundant somata in the $\mathrm{VZ}$ and their associated radial fibers but no somata above the VZ in E14.5 En1; Ptpn $11^{\text {CKO }}$ cerebellum (Fig. $5 L$ ). Finally, to rule out a failure of BG survival due to the deletion of Ptpn11, we analyzed apoptosis by IF for Casp3. We detected no difference in the number of Casp $3^{+}$cells on cerebellar sections between the control and En1;Ptpn11 ${ }^{\text {CKO }}$ cerebellum at E14.5, E16.5, and postnatal stages (data not shown). Together, our data show that RG fail to transform into BG in the absence of Ptpn11.

\section{Shp2 regulates Fgf8/ERK signaling in the developing cerebellum}

Ptpn 11 has been implicated in multiple intracellular signaling pathways including Ras/ERK, PI3K/AKT, and JAK/STAT (Feng, 2007). To determine the signaling pathways regulated by Shp2 in the developing cerebellum, we quantified the levels of activated-phosphorylated (p) forms of ERK1/2, AKT, and STAT3 by Western blotting. We found that loss of Shp2 compromised ERK activation, but had no apparent effect on AKT, in the posterior midbrain and cerebellum of En1;Ptpn11 ${ }^{\text {CKO }}$ embryos at E13.5 (Fig. 6A). pSTAT3 was not detected in both wild-type and mutant cerebella at E13.5 (data not shown). In agreement with the Western blot data, immunostaining showed that pERK was dramatically reduced in the mutant midbrain and cerebellum at E13.5 (Fig. 6B,C). Interestingly, despite the depletion of the Shp2 protein as early as E8.5 (Fig. 1B), no significant alterations of pERK were detected in the neural tube of En1;Ptpn11 ${ }^{C K O}$ embryos until E10.5, when pERK signals appeared reduced in the midbrain and the cerebellar primordium particularly in areas distant from the isthmus (Fig. 6L; data not shown). Therefore, Shp2 is required to sustain ERK signaling in the developing cerebellum.

Genetic and embryological studies have demonstrated that Fgf8/ERK signaling plays an important role in the development of the midbrain and cerebellum (Sato et al., 2004). To investigate if Shp2 regulates this signaling pathway, we first analyzed the expression of Fgf8-target genes that encode the feedback antagonist Sprouty proteins (Spry1 and Spry2), as well as the Ets family transcription factors (Etv4 and Etv5). ISH analysis showed that the expression of these genes was noticeably reduced in the cerebellum of En1;Ptpn11 ${ }^{\text {CKO }}$ embryos at E11.5 and E12.5 (Fig. 6D$G)$, suggesting that inactivation of Shp2 weakens FGF/ERK signaling from E11.5 onward.

To confirm that Ptpn11 is essential for Fgf8 function, we investigated the genetic interaction between $P \operatorname{tpn} 11$ and $F g f 8$. We reasoned that if Fgf8 and Shp2 function cooperatively, removing 
one copy of $F g f 8$, which by itself has no effect on midbrain and cerebellum development (Guo et al., 2010), would enhance the phenotype of the En1;Ptpn $11^{C K O} \mathrm{mu}-$ tation. Indeed, more severe truncation of the midbrain and complete deletion of the

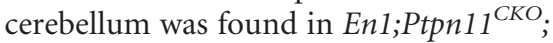
$\mathrm{Fg} 8^{+/-}$embryos (Fig. $\left.6 \mathrm{H}-\mathrm{J}\right)$. Importantly, in contrast to the persistence of pERK at the junction between the midbrain and cerebellum in En1;Ptpn $11^{\text {CKO }}$ embryos at E11.5, the pERK immunoreactivity was completely missing in this region in En1;Ptpn $11^{\mathrm{CKO}} ; \mathrm{Fgf8} 8^{+/-}$embryos at E11.5 (Fig. $6 L, M$ ), indicating that Fgf8 was responsible for the residual pERK activity in the En1;Ptpn $11^{C K O}$ cerebellum. Together, our data show that Shp2 interacts with Fgf8 signaling and is essential for the ERK signaling transduction in the developing midbrain and cerebellum.

\section{Expressing constitutively active MEK1 rescues $B G$ induction and cerebellar foliation}

Interestingly, our analyses revealed strong pERK immunoreactivity in the VZ and radial fibers in the wild-type cerebellum at E13.5 (Fig. 7A). Colocalization analyses showed that pERK was present in a subset of $\mathrm{BLBP}^{+}$and Sox ${ }^{+}$somata in the VZ of the cerebellum at E14.5 (Fig. 7B,C). Furthermore, pERK immunoreactivity was colocalized with $\mathrm{BLBP}^{+}$basal fibers, including their end feet at the pial surface, in the cerebellum at E14.5 (Fig. 7D). These observations, together with the specific loss of pERK and BG in En1;Ptpn $11^{C K O}$ cerebella, suggest that ERK acts downstream and mediates Shp2 function to induce BG. To test this hypothesis, we generated En1;Ptpn $11^{\text {CKO; }}$ $R 26^{+/ M E K 1 D D}$ embryos to simultaneously remove Ptpn11 and express the constitutively active MEK1, which activates ERK independently of extracellular signals (Cowley et al., 1994), in the cerebellar anlage. Nascent BG were initially detected in the posterior part of the cerebellar VZ around E14.5 in wild-type embryos (Figs. $5 A, E, 7 E$ ). Interestingly, although $M E K 1^{D D}$ was expressed throughout midbrain and cerebellar progenitors in $E n 1^{\text {cre/+}} ; R 26^{+/ M E K 1 D D}$ embryos as early as E8.5, nascent BG were correctly induced at approximately the same number in the posterior part of the cerebellum in these $M E K 1^{D D}$ transgenic embryos at E14.5, suggesting that MEK/ERK activation is not sufficient to accelerate or enhance BG induction (Fig. $7 F$ ). As expected, pERK signals were restored in the En1; Ptpn $11^{C K O} ; R 26^{+/ M E K 1 D D}$ cerebellum (data not shown). In contrast to the complete absence of Sox $9^{+} / \mathrm{BLBP}^{+}$cells between the VZ and EGL in the En1;Ptpn $11^{C K O}$ cerebellum, abundant Sox ${ }^{+} /$ $\mathrm{BLBP}^{+}$cells were detected in the En1;Ptpn11 ${ }^{\text {CKO }} ; R_{2} 6^{+/ M E K 1 D D}$ cerebella (Fig. $7 \mathrm{H}, I$ ). Importantly, the Sox $9^{+} / \mathrm{BLBP}^{+}$cells in the subcortical region displayed radial $\mathrm{BLBP}^{+}$fibers extending to the pial surface, indicating a bona fide BG identity (Fig. $7 J, K, T$ ).
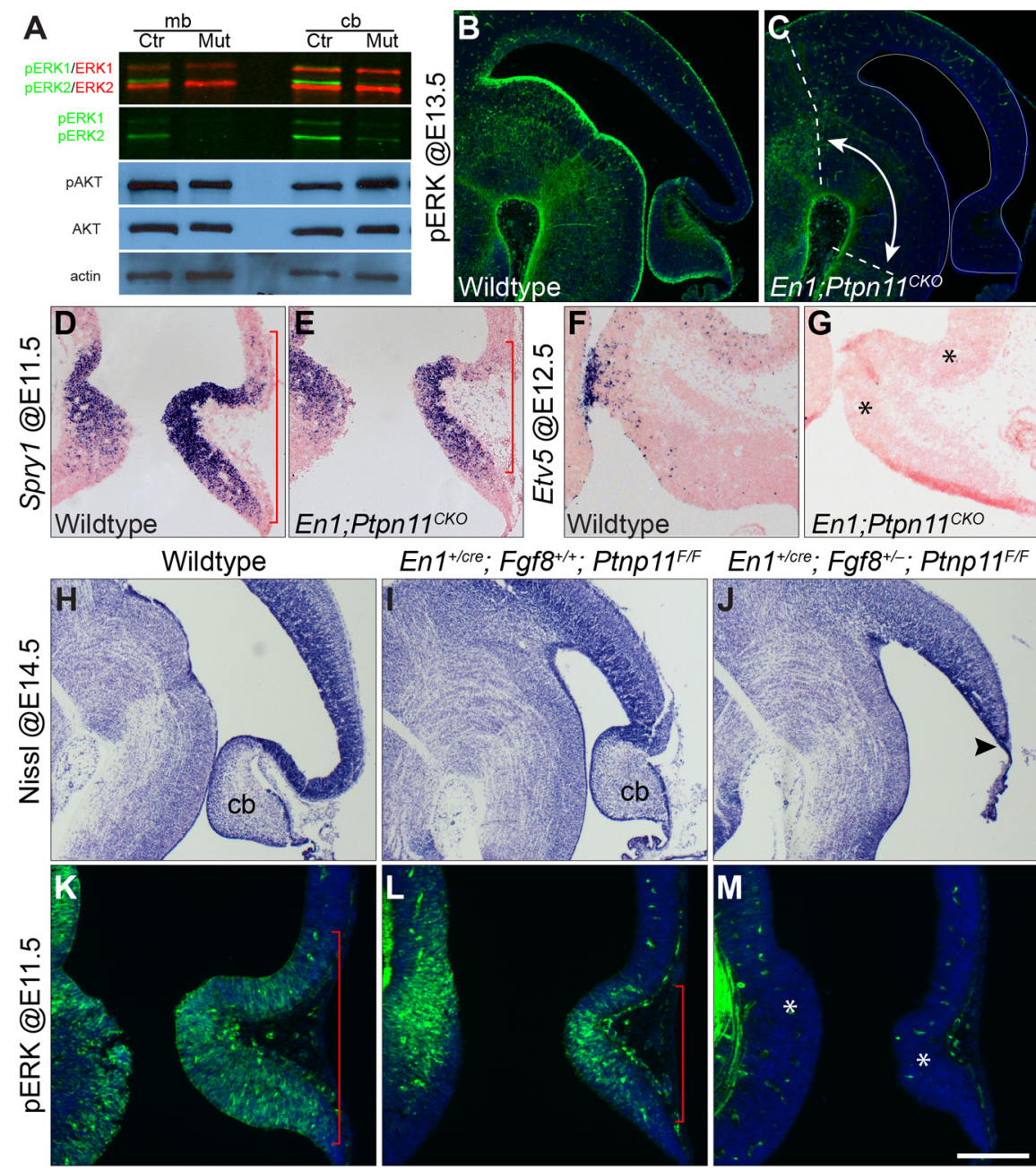

Figure 6. Shp2 regulates the Fgf8/ERK signaling pathways in the developing cerebellum. $\boldsymbol{A}$, Western blots analysis of activation of ERK and AKT in the E13.5 posterior midbrain and cerebellum. $B, C$, IF for pERK on sagittal sections of E13.5 brains for the indicated En1:Ptpn 11 CKO mutant with only one copy of the Fgf8 gene. $K-M$ IF for PERK on sagittal sections of E11.5 embryos of indicated genotypes. Brackets demarcate the range of pERK immunoreactivity; asterisks indicate the loss of pERK. Scale bar, $\boldsymbol{B}, \boldsymbol{C}, 50 \mu \mathrm{m} ; \boldsymbol{D}$ $\boldsymbol{E}, 150 \mu \mathrm{m} ; \boldsymbol{F}, \boldsymbol{G}, 170 \mu \mathrm{m} ; \boldsymbol{H}-\boldsymbol{J}, 125 \mu \mathrm{m} ; \boldsymbol{K}-\boldsymbol{M}, 100 \mu \mathrm{m}$.

These results demonstrate that expressing $M E K 1^{D D}$ rescues BG formation in the En1;Ptpn $11^{C K O}$ cerebellum.

We reasoned that if the loss of BG had caused the uncoupling of the inward GCP accumulation from the folding of PCL and pial membrane, a rescue of BG should restore cerebellar foliation in the En1;Ptpn $11^{C K O}$ cerebellum. At P2, both En $1^{\text {cre }}$; $R 26^{+/ M E K 1 D D}$ and En1;Ptpn11 ${ }^{C K O} ; R 26^{+/ M E K 1 D D}$ mice displayed elongated cerebella along the rostrocaudal axis, and abnormal pattern of foliation of the cerebellar cortex (Fig. $7 L-N$ ). However, the formation of cerebellar fissures was restored in En1; Ptpn $11^{C K O} ; R 26^{+/ M E K 1 D D}$ mice as demonstrated by the concerted folding of EGL, PCL, and basement membrane (Fig. 7O-T). Abnormally thickened EGL was still detected in the anterior lobules of the En1;Ptpn11 ${ }^{C K O} ; R 26^{+/ M E K 1 D D}$ cerebellum (Fig. 7Q), suggesting that expressing $M E K 1^{D D}$ may not rescue all the defects caused by the loss of Shp2. Nevertheless, our data demonstrate that Shp2 controls BG generation and foliation of the cerebellar cortex through the MEK/ERK signaling cascade. 

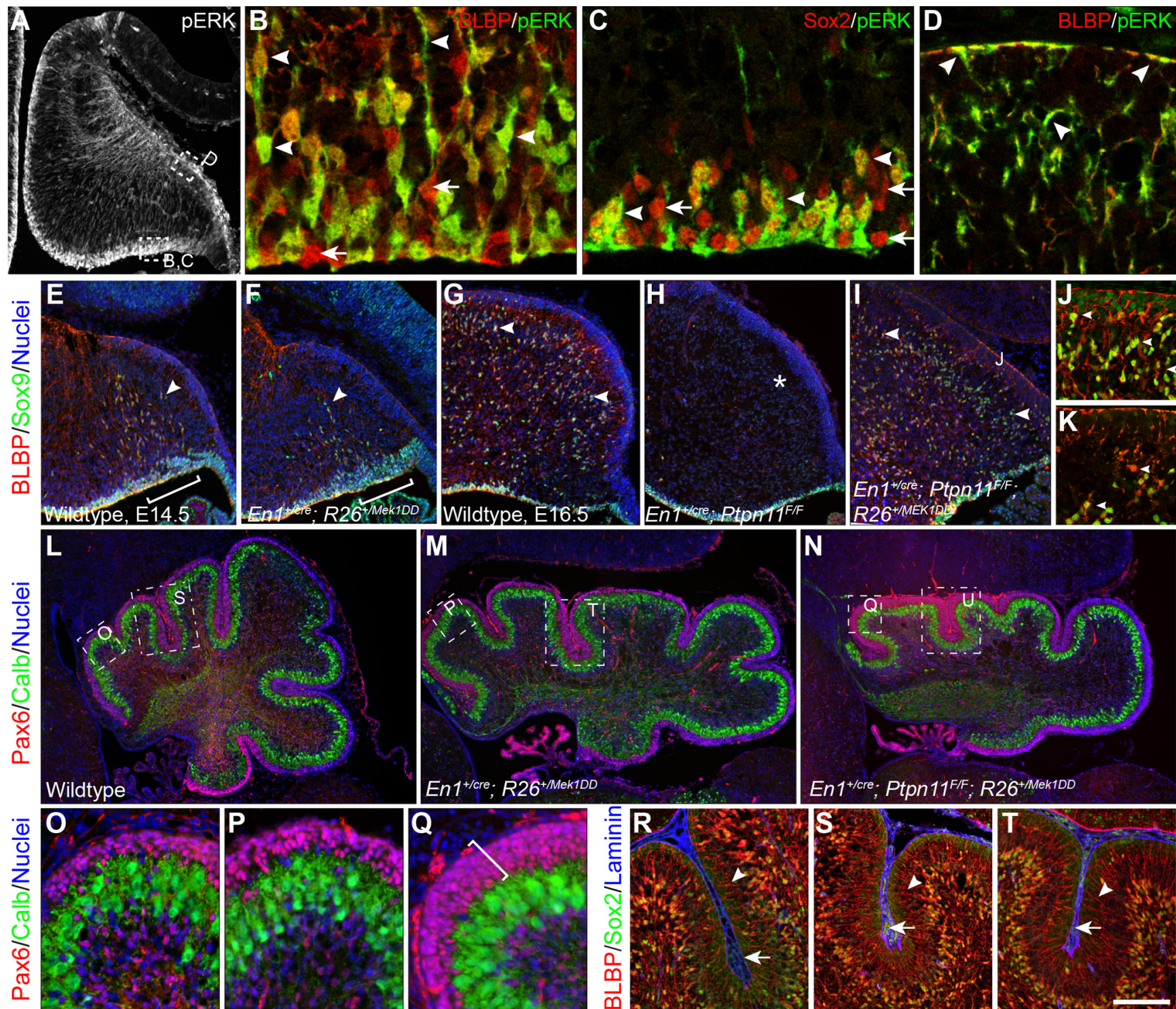

Figure 7. Expressing constitutively active MEK1 rescues formation of $B G$ and foliation of the cerebellum in En 1;Ptpn $11^{C K O}$ mutants. $A$, IF for pERK on sagittal sections of wild-type cerebellum at E13.5. $\boldsymbol{B}-\boldsymbol{D}$, Colocalization analyses of pERK with BLBP $(\boldsymbol{B}, \boldsymbol{D})$ and Sox2 $(\boldsymbol{C})$ on sagittal sections of E14.5 cerebella. Arrowheads show pERK immunoreactivity in a subset of BLBP ${ }^{+}$or Sox2 ${ }^{+}$somata $(\boldsymbol{B}, \boldsymbol{C})$, and in most of the BLBP${ }^{+}$fibers and end feet at the pial membrane $(\boldsymbol{D})$; arrows indicate the absence of pERK in some BLBP ${ }^{+}$or Sox2 ${ }^{+}$somata. $\boldsymbol{E}-\boldsymbol{T}$, IF analyses on sagittal sections of the cerebellum at E14.5 $(\boldsymbol{E}, \boldsymbol{F}), \mathrm{E} 16.5(\boldsymbol{G}-\boldsymbol{K})$, and P2 $(\boldsymbol{L}-\boldsymbol{T})$. Markers and genotypes are, respectively, indicated to the left and to the low-left corner of the images. Brackets demarcate the posterior area in the cerebellar VZ where nascent $\mathrm{BG}$ are first detected; asterisk in $\boldsymbol{H}$ shows the lack of $\mathrm{BLBP}{ }^{+} / \mathrm{Sox} 9^{+} \mathrm{BG}$; arrowheads denote $\mathrm{BG}(\boldsymbol{E}-\boldsymbol{K})$. Arrows indicate the basement membrane within the fissure $(\boldsymbol{R}-\boldsymbol{T})$. Scale bar, $\boldsymbol{A}, 175 \mu \mathrm{m} ; \boldsymbol{B}-\boldsymbol{D}, 20 \mu \mathrm{m} ; \boldsymbol{E}-\boldsymbol{F}, 150 \mu \mathrm{m} ; \boldsymbol{G}-\mathbf{I}, 150 \mu \mathrm{m} ; \boldsymbol{L}-\mathbf{N}, 270 \mu \mathrm{m}$.

\section{Discussion}

Shp2 is essential for BG generation

Using an exhaustive list of molecular markers (Tnc, Slc1a3, Sox2, Sox9, Hes1, BLBP, RC2, GFAP), morphologic features (radial fibers in the molecular layer), and backfill-labeling techniques (to label BG through their basal processes from the pial surfaces), we show that the En1;Ptpn11 ${ }^{\text {CKO }}$ cerebella do not form BG. Our results support the notion that inactivation of Ptpn11 prevents RG from transforming into BG. We rule out the possibility that BG might be generated but undergo apoptosis. Collectively, our results demonstrate that Shp2 is essential for BG induction. Although numerous mutations leading to reduction and/or abnormal morphological differentiation of BG have been reported (Xu et al., 2013), our study, to our best knowledge, is the first to characterize a genetic mutation that blocks $\mathrm{BG}$ induction in rodents.
By analyzing cell-specific markers, we show that Purkinje cells, interneurons, granule cells, oligodendrocyte progenitors and precursors, and astrocytes are present in the En1;Ptpn $11^{\text {CKO }}$ cerebellum, indicating that the major cerebellar cell types, except for BG, are produced in the absence of Shp2. However, without extensive additional birth-date and cell-counting studies, we cannot rule out that the generation of other VZ-derived cell types are completely unaffected. In this study, we found that a population of embryonic cerebellar cells coexpressing Sox2, Sox9, Hes1, Ki67, and BLBP, which we provisionally named "cerebellar basal progenitors," emerge from the cerebellar VZ after E14.5. Many of these basal progenitors reach the cerebellar cortex and display characteristic BG features at later stages, suggesting that cerebellar basal progenitors give rise to BG. Cerebellar basal progenitors may also form non-BG cells, particularly oligodendrocytes, as we found 
that both BG and oligodendrocyte progenitors were missing in the En1;Ptpn 11 ${ }^{C K O}$ cerebellum at E16.5. Our observations are in agreement with a previous report that BG and oligodendrocytes may share common progenitors in the cerebellum (Chung et al., 2013). Significantly, we found that cerebellar basal progenitors, as well as oligodendrocytes, re-emerged in the En1;Ptpn $11^{\text {CKO }}$ cerebellum after E18.5 (Fig. 4D,M), suggesting that Shp2 is essential for the generation of cerebellar basal progenitors between E14.5 and E16.5, but not thereafter. In agreement with the persistence of Sox $2^{+}$and GFAP ${ }^{+}$cells, which are progenitors of basket and stellate interneurons (Silbereis et al., 2009), we observed a progressive increase in $\mathrm{Pax} 2{ }^{+}$interneuron precursors in the cortical area of the En 1;Ptpn $11^{\text {CKO }}$ cerebellum from P2 to P8 (data not shown). However, the number of Pax2 ${ }^{+}$cells in the cerebellar cortex in En1;Ptpn $11^{C K O}$ mice appeared lower than that in the control. Collectively, our data suggest that Shp2 function is essential for BG formation in the mouse cerebella.

\section{Shp2 regulates $\mathrm{BG}$ formation via the FGF/ERK signaling pathway}

Recruitment of Shp2 to the tyrosine phosphorylation sites on FRS $2 \alpha$ is involved in FGF stimulation of the Ras/ERK signaling cascade (Hadari et al., 1998, 2001). Furthermore, Shp2 can promote FGF/ERK signaling by inhibiting the function of Sprouty proteins, suppressors of Ras signaling (Pan et al., 2010). Several lines of evidence indicate that Shp2 regulates cerebellar development via promoting the FGF/ERK signaling pathway. First, loss of Shp2 abolishes ERK signaling in the cerebellum after E13.5. Second, Ptpn11 genetically interacts with Fgf8 in cerebellar formation. Third, deletion of the three FGF receptor genes, Fgfr1, Fgfr2, and Fgfr 3 using a Nestin-cre transgene results in a similar cerebellar phenotype (Lin et al., 2009) and a complete loss of BG (data not shown) as in En1;Ptpn $11^{C K O}$ mutants. Last, expression of constitutively active MEK1 restores BG formation in the En1;Ptpn11 ${ }^{C K O}$ cerebellum. Therefore, Shp2 regulates cerebellar and BG formation through the FGF/ERK signaling pathway.

Interestingly, pERK immunoreactivity was undetectable in the cerebellar VZ when basal progenitors reappeared in the En1; Ptpn11 ${ }^{\text {CKO }}$ cerebellum at E18.5 (data not shown). Furthermore, these late-born cerebellar basal progenitors lacked the normal basal process and failed to form BG. Therefore, ERK signaling is required in a limited time window (between E14.5 and E16.5) to promote RG to form cerebellar basal progenitors that are capable of forming BG. Future experiments will determine whether ERK activation is essential to induce basal progenitors that inherit the radial basal process to form $B G$.

\section{Shp2 is not intrinsically required in the GCP lineage}

It has been suggested that Shp2 regulates formation of the laminar cerebellar cortex by controlling granule cell migration via mediating Cxcl12/Cxcr4 signaling (Hagihara et al., 2009). In the current study, we found that removing Ptpn11 in the EGL had no discernible effect on cerebellar development. Examination of Shp2 protein expression demonstrated a specific removal of Shp 2 proteins in the GCP lineage in Atoh1;Ptpn $11^{\text {CKO }}$ mice. Therefore, Shp2 is not cell autonomously required in the GCP lineage for normal cerebellar formation. The abnormal GCP development found in En1;Ptpn $11^{\text {CKO }}$ cerebellum is therefore likely a secondary effect, possibly caused by decreased mitogenic Shh activity in the EGL arising from the defective migration of Purkinje cells observed at $\mathrm{P} 2$. Our in vivo data do not rule out the possibility that Shp2 is involved in normal Cxcl12/Cxcr4 signaling transduction as demonstrated by previous biochemical and explant culture experiments (Hagihara et al., 2009). However, a defect, if there is any, in the Cxcl12/Crxr4 signaling due to the loss of Shp2 in the GCP lineage must have been fully compensated during in vivo development.

\section{BG may participate in orchestrating the folding of the cerebellar cortex}

It is generally believed that GCP dictate the tangential expansion of the cerebellar surface and hence the stereotypical foliation of the cerebellar cortex. However, previous findings have implicated abnormal BG development in defective cerebellar fissure formation (Delaney et al., 1996; Kaartinen et al., 2001; Qu and Smith, 2005; Yue et al., 2005; Weller et al., 2006; Hoser et al., 2007; Ma et al., 2012). In the current study, we find that the GCP inward accumulation, which is believed to initiate formation of the anchoring centers (Sudarov and Joyner, 2007), persists in the absence of BG in the En1;Ptpn $11^{\text {CKO }}$ cerebellum. However, the GCP invagination fails to cause folding of the PCL and pial basement membrane. Furthermore, we demonstrate that rescuing BG formation by reactivating the MEK/ERK pathway restores both the formation and organization of cerebellar folia. Our findings suggest that the initialization of the inward accumulation is intrinsic to GCP, while BG plays an essential role to orchestrate the folding of the cerebellar cortex by coordinating the invagination of GCP with that of PCL and the pial membrane (Fig. 2I).

The precise mechanism underlying BG function to orchestrate the convolution of the cerebellar cortex remains to be determined. It is possible that adhesion of pial basement membranes by BG generates the necessary tension for the normal cortical folding as previously suggested (Van Essen, 1997; Ma et al., 2012). Alternatively, proliferation of BG may increase the amount of radial units, which in turn regulate the expansion of the cerebellar surfaces. Corroborating this idea, we found that BG were highly proliferative at least until P15, and they displayed more robust proliferation in the crowns (which prospectively requires more expansion of the cerebellar surfaces) than at the base of the cerebellar fissures (A.W. Leung and J.Y.H. Li, unpublished observations). Interestingly, BG bear remarkable similarity in their ontogenesis and molecular features to basal RG, a type of newly identified neural progenitors that are intimately associated with cortical surface expansion and gyrification in the human cerebral cortex (Hansen et al., 2010; Lui et al., 2011; Reillo et al., 2011; Nonaka-Kinoshita et al., 2013; Stahl et al., 2013). It is possible that formation of BG and basal RG represent a convergent mechanism underlying the surface expansion and gyrification of cerebellar and cerebral cortices.

In summary, we have defined the cellular lineage and the signaling pathway by which Ptpn11 exerts its function in regulating cerebellar development. We demonstrate that Shp2-dependent ERK activation promotes the progression of neural progenitors in the cerebellar VZ to generate cerebellar basal progenitors that are capable of forming BG. Moreover, we show that $\mathrm{BG}$ are essential for orchestrating the folding of the cerebellar cortex. Interestingly, expressing constitutively active MEK1 did not accelerate or enhance BG generation in wild-type embryos, indicating that ERK signaling is essential but not sufficient in BG induction. In the future, it will be important to define how ERK interacts with other signaling pathways to control the expression and/or function of intrinsic determinant(s) for BG specification. This information may provide insights to the generation of basal RG in the neocortex.

\section{References}

Alcock J, Sottile V (2009) Dynamic distribution and stem cell characteristics of Sox1-expressing cells in the cerebellar cortex. Cell Res 19:1324-1333. CrossRef Medline

Alcock J, Scotting P, Sottile V (2007) Bergmann glia as putative stem cells of the mature cerebellum. Med Hypotheses 69:341-345. CrossRef Medline

Anthony TE, Klein C, Fishell G, Heintz N (2004) Radial glia serve as neuronal progenitors in all regions of the central nervous system. Neuron 41: 881-890. CrossRef Medline 
Chan RJ, Feng GS (2007) PTPN11 is the first identified proto-oncogene that encodes a tyrosine phosphatase. Blood 109:862-867. Medline

Chung SH, Guo F, Jiang P, Pleasure DE, Deng W (2013) Olig2/Plp-positive progenitor cells give rise to Bergmann glia in the cerebellum. Cell Death Dis 4:e546. CrossRef Medline

Corrales JD, Rocco GL, Blaess S, Guo Q, Joyner AL (2004) Spatial pattern of sonic hedgehog signaling through Gligenes during cerebellum development. Development 131:5581-5590. CrossRef Medline

Cowley S, Paterson H, Kemp P, Marshall CJ (1994) Activation of MAP kinase kinase is necessary and sufficient for PC12 differentiation and for transformation of NIH 3T3 cells. Cell 77:841-852. CrossRef Medline

Delaney CL, Brenner M, Messing A (1996) Conditional ablation of cerebellar astrocytes in postnatal transgenic mice. J Neurosci 16:6908-6918. Medline

Feng GS (2007) Shp2-mediated molecular signaling in control of embryonic stem cell self-renewal and differentiation. Cell Res 17:37-41. CrossRef Medline

Gauthier AS, Furstoss O, Araki T, Chan R, Neel BG, Kaplan DR, Miller FD (2007) Control of CNS cell-fate decisions by SHP-2 and its dysregulation in Noonan syndrome. Neuron 54:245-262. CrossRef Medline

Guo Q, Li K, Sunmonu NA, Li JY (2010) Fgf8b-containing spliceforms, but not Fgf8a, are essential for Fgf8 function during development of the midbrain and cerebellum. Dev Biol 338:183-192. CrossRef Medline

Hadari YR, Kouhara H, Lax I, Schlessinger J (1998) Binding of Shp2 tyrosine phosphatase to FRS2 is essential for fibroblast growth factor-induced PC12 cell differentiation. Mol Cell Biol 18:3966-3973. Medline

Hadari YR, Gotoh N, Kouhara H, Lax I, Schlessinger J (2001) Critical role for the docking-protein FRS2 alpha in FGF receptor-mediated signal transduction pathways. Proc Natl Acad Sci U S A 98:8578-8583. CrossRef Medline

Hagihara K, Zhang EE, Ke YH, Liu G, Liu JJ, Rao Y, Feng GS (2009) Shp2 acts downstream of SDF-1alpha/CXCR4 in guiding granule cell migration during cerebellar development. Dev Biol 334:276-284. CrossRef Medline

Hansen DV, Lui JH, Parker PR, Kriegstein AR (2010) Neurogenic radial glia in the outer subventricular zone of human neocortex. Nature 464:554561. CrossRef Medline

Hatten ME (1999) Central nervous system neuronal migration. Annu Rev Neurosci 22:511-539. CrossRef Medline

Hoser M, Baader SL, Bösl MR, Ihmer A, Wegner M, Sock E (2007) Prolonged glial expression of Sox 4 in the CNS leads to architectural cerebellar defects and ataxia. J Neurosci 27:5495-5505. CrossRef Medline

Iino M, Goto K, Kakegawa W, Okado H, Sudo M, Ishiuchi S, Miwa A, Takayasu Y, Saito I, Tsuzuki K, Ozawa S (2001) Glia-synapse interaction through $\mathrm{Ca}^{2+}$ permeable AMPA receptors in Bergmann glia. Science 292:926-929. CrossRef Medline

Kaartinen V, Gonzalez-Gomez I, Voncken JW, Haataja L, Faure E, Nagy A, Groffen J, Heisterkamp N (2001) Abnormal function of astroglia lacking Abr and Bcr RacGAPs. Development 128:4217-4227. Medline

Ke Y, Zhang EE, Hagihara K, Wu D, Pang Y, Klein R, Curran T, Ranscht B, Feng GS (2007) Deletion of Shp2 in the brain leads to defective proliferation and differentiation in neural stem cells and early postnatal lethality. Mol Cell Biol 27:6706-6717. CrossRef Medline

Kimmel RA, Turnbull DH, Blanquet V, Wurst W, Loomis CA, Joyner AL (2000) Two lineage boundaries coordinate vertebrate apical ectodermal ridge formation. Genes Dev 14:1377-1389. Medline

Koirala S, Corfas G (2010) Identification of novel glial genes by single-cell transcriptional profiling of Bergmann glial cells from mouse cerebellum. PLoS One 5:e9198. CrossRef Medline

Li JY, Lao Z, Joyner AL (2002) Changing requirements for Gbx2 in development of the cerebellum and maintenance of the mid/hindbrain organizer. Neuron 36:31-43. CrossRef Medline

Lin Y, Chen L, Lin C, Luo Y, Tsai RY, Wang F (2009) Neuron-derived FGF9 is essential for scaffold formation of Bergmann radial fibers and migration of granule neurons in the cerebellum. Dev Biol 329:44-54. CrossRef Medline

Lui JH, Hansen DV, Kriegstein AR (2011) Development and evolution of the human neocortex. Cell 146:18-36. CrossRef Medline

Ma S, Kwon HJ, Huang Z (2012) Ric-8a, a guanine nucleotide exchange factor for heterotrimeric $\mathrm{G}$ proteins, regulates Bergmann glia-basement membrane adhesion during cerebellar foliation. J Neurosci 32:14979-14993. CrossRef Medline

Malatesta P, Hack MA, Hartfuss E, Kettenmann H, Klinkert W, Kirchhoff F,
Götz M (2003) Neuronal or glial progeny: regional differences in radial glia fate. Neuron 37:751-764. CrossRef Medline

Mohi MG, Neel BG (2007) The role of Shp2 (PTPN11) in cancer. Curr Opin Genet Dev 17:23-30. CrossRef Medline

Nonaka-Kinoshita M, Reillo I, Artegiani B, Angeles Martínez-Martínez MÁ, Nelson M, Borrell V, Calegari F (2013) Regulation of cerebral cortex size and folding by expansion of basal progenitors. EMBO J 32:1817-1828. CrossRef Medline

Pan Y, Carbe C, Powers A, Feng GS, Zhang X (2010) Sprouty2-modulated Kras signaling rescues Shp2 deficiency during lens and lacrimal gland development. Development 137:1085-1093. CrossRef Medline

Qu Q, Smith FI (2005) Neuronal migration defects in cerebellum of the Largemyd mouse are associated with disruptions in Bergmann glia organization and delayed migration of granule neurons. Cerebellum 4:261270. CrossRef Medline

Reillo I, de Juan Romero C, García-Cabezas MÁ, Borrell V (2011) A role for intermediate radial glia in the tangential expansion of the mammalian cerebral cortex. Cereb Cortex 21:1674-1694. CrossRef Medline

Sato T, Joyner AL, Nakamura H (2004) How does Fgf signaling from the isthmic organizer induce midbrain and cerebellum development? Dev Growth Differ 46:487-494. CrossRef Medline

Silbereis J, Cheng E, Ganat YM, Ment LR, Vaccarino FM (2009) Precursors with glial fibrillary acidic protein promoter activity transiently generate GABA interneurons in the postnatal cerebellum. Stem Cells 27:11521163. CrossRef Medline

Sottile V, Li M, Scotting PJ (2006) Stem cell marker expression in the Bergmann glia population of the adult mouse brain. Brain Res 1099:8-17. CrossRef Medline

Srinivasan L, Sasaki Y, Calado DP, Zhang B, Paik JH, DePinho RA, Kutok JL, Kearney JF, Otipoby KL, Rajewsky K (2009) PI3 kinase signals BCRdependent mature B cell survival. Cell 139:573-586. CrossRef Medline

Stahl R, Walcher T, De Juan Romero C, Pilz GA, Cappello S, Irmler M, Sanz-Aquela JM, Beckers J, Blum R, Borrell V, Götz M (2013) Trnp1 regulates expansion and folding of the mammalian cerebral cortex by control of radial glial fate. Cell 153:535-549. CrossRef Medline

Sudarov A, Joyner AL (2007) Cerebellum morphogenesis: the foliation pattern is orchestrated by multicellular anchoring centers. Neural Dev 2:26. CrossRef Medline

Tartaglia M, Mehler EL, Goldberg R, Zampino G, Brunner HG, Kremer H, van der Burgt I, Crosby AH, Ion A, Jeffery S, Kalidas K, Patton MA, Kucherlapati RS, Gelb BD (2001) Mutations in PTPN11, encoding the protein tyrosine phosphatase SHP-2, cause Noonan syndrome. Nat Genet 29:465-468. CrossRef Medline

Van Essen DC (1997) A tension-based theory of morphogenesis and compact wiring in the central nervous system. Nature 385:313-318. CrossRef Medline

Wang VY, Zoghbi HY (2001) Genetic regulation of cerebellar development. Nat Rev Neurosci 2:484-491. CrossRef Medline

Weller M, Krautler N, Mantei N, Suter U, Taylor V (2006) Jagged1 ablation results in cerebellar granule cell migration defects and depletion of Bergmann glia. Dev Neurosci 28:70-80. CrossRef Medline

Xu H, Yang Y, Tang X, Zhao M, Liang F, Xu P, Hou B, Xing Y, Bao X, Fan X (2013) Bergmann glia function in granule cell migration during cerebellum development. Mol Neurobiol 47:833-844. CrossRef Medline

Yamada K, Watanabe M (2002) Cytodifferentiation of Bergmann glia and its relationship with Purkinje cells. Anat Sci Int 77:94-108. CrossRef Medline

Yang H, Xie X, Deng M, Chen X, Gan L (2010) Generation and characterization of Atoh1-Cre knock-in mouse line. Genesis 48:407-413. CrossRef Medline

Yang W, Klaman LD, Chen B, Araki T, Harada H, Thomas SM, George EL, Neel BG (2006) An Shp2/SFK/Ras/Erk signaling pathway controls trophoblast stem cell survival. Dev Cell 10:317-327. CrossRef Medline

Yang W, Wang J, Moore DC, Liang H, Dooner M, Wu Q, Terek R, Chen Q, Ehrlich MG, Quesenberry PJ, Neel BG (2013) Ptpn11 deletion in a novel progenitor causes metachondromatosis by inducing hedgehog signalling. Nature 499:491-495. CrossRef Medline

Yuasa S (1996) Bergmann glial development in the mouse cerebellum as revealed by tenascin expression. Anat Embryol 194:223-234. Medline

Yue Q, Groszer M, Gil JS, Berk AJ, Messing A, Wu H, Liu X (2005) PTEN deletion in Bergmann glia leads to premature differentiation and affects laminar organization. Development 132:3281-3291. CrossRef Medline 